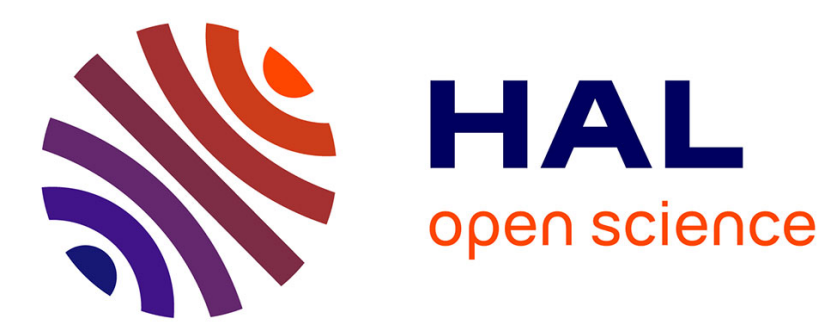

\title{
Carbon Price Drivers: An Updated Literature Review
} Julien Chevallier

\section{To cite this version:}

Julien Chevallier. Carbon Price Drivers: An Updated Literature Review. 2011. halshs-00586513

\section{HAL Id: halshs-00586513 \\ https://shs.hal.science/halshs-00586513}

Preprint submitted on 16 Apr 2011

HAL is a multi-disciplinary open access archive for the deposit and dissemination of scientific research documents, whether they are published or not. The documents may come from teaching and research institutions in France or abroad, or from public or private research centers.
L'archive ouverte pluridisciplinaire HAL, est destinée au dépôt et à la diffusion de documents scientifiques de niveau recherche, publiés ou non, émanant des établissements d'enseignement et de recherche français ou étrangers, des laboratoires publics ou privés. 


\title{
Carbon Price Drivers: An Updated Literature Review
}

\author{
Julien Chevallier $^{1^{*}}$ \\ University Paris Dauphine, France \\ April 2011
}

\begin{abstract}
Since the creation of the European Union Emissions Trading Scheme (EU ETS) in 2005, a burgeoning academic literature has emerged to identify the factors that shape the price of carbon, where one European Union Allowance is equal to one ton of $\mathrm{CO}_{2}$-equivalent emitted in the atmosphere. Thus, there is a need for an updated and thorough literature review on the state-ofthe-art on topic that this paper aims to fulfill. Namely, we consider the main econometric studies that have been recently published in the academic literature, which feature the influence of the following determinants to explain the variation of the price of carbon: institutional decisions; energy prices and weather events; macroeconomic and financial market shocks. The paper concludes with some directions for future research in this area.
\end{abstract}

Keywords: Carbon Price; Banking Borrowing; Energy Prices; Macroeconomy; Financial Markets; Econometrics

\section{INTRODUCTION}

Ellerman and Buchner (2007), and Convery and Redmond (2007) masterly produced an early literature review on the carbon price development in their respective articles for the first issue of the Review of Environmental Economics and Policy. This work was further elaborated by Convery (2009) alone in his reflections on the emerging literature on emissions trading in Europe, and compiled in an edited volume by Ellerman, Convery and De Perthuis (2010). Zhang and Wei (2010) provided further insights, based on evidence from the operating mechanism and economic effects of the newly created EU Emissions Trading Scheme (EU ETS).

Building upon these initial contributions, this paper provides a systematic update on the cutting-edge literature of carbon price drivers from 2007 onwards. It reviews mainly economic

\footnotetext{
${ }^{1 *}$ Corresponding Author. Address for correspondence : University Paris Dauphine, CGEMP/LEDa, Place du Marechal de Lattre de Tassigny, 75016 Paris, France. Email : julien.chevallier@dauphine.fr Phone : +33(0)1 44054464 Fax: +33 (0)1 44054484
} 
and econometric studies which have identified inter-relationships between the price of $\mathrm{CO}_{2}$ on the one hand, and its main fundamentals that allow to explain and forecast its variation overtime on the other hand. By doing so, this paper calls for more research in this promising area, since many puzzles remain to be solved by researchers in empirical work, especially concerning the adjustment of carbon prices to the macroeconomic environment.

At first glance, this paper features that the price of carbon is classically driven by the balance between supply and demand, and by other factors related to market structure and institutional policies. On the supply side, the number of allowances distributed is determined by each Member-State through National Allocation Plans (NAPs), which are then harmonized at the EUlevel by the European Commission. On the demand side, the use of $\mathrm{CO}_{2}$ allowances is a function of expected $\mathrm{CO}_{2}$ emissions. In turn, the level of emissions depends on a large number of factors, such as unexpected fluctuations in energy demand, energy prices (e.g., oil, gas, coal) and weather conditions (temperatures, rainfall and wind speed). The demand for allowances can be affected by economic growth and financial markets as well, but that latter impact needs to be further assessed in the academic community.

The remainder of the paper is structured as follows. Section 2 explains how institutional decisions affect the price path of carbon. Section 3 introduces the mechanisms at stake between the price of $\mathrm{CO}_{2}$ and the price of other energy markets. In addition, it provides the main intuition behind the influence of extreme weather and temperatures events. Section 4 develops the links with the macroeconomic and financial markets. Section 5 briefly concludes.

\section{INSTITUTIONAL DECISIONS}

In this section, we consider two main categories of institutional decisions that are likely to impact the price of carbon: $(i)$ the emissions shortfall factor, defined as the difference between verified emissions and allocated allowances within a given compliance year, and (ii) the effects of banning banking from phase I to phase II of the scheme.

\subsection{The emissions shortfall factor}

The best example of the influence of institutional decisions on the price development of carbon may be found during the year 2006. Indeed, during that year Ellerman and Buchner (2008) report that the first report of verified emissions published by the European Commission at the aggregated EU-wide level has had a dramatic impact on the carbon price, which fell by almost fifty percent in a few days. The main reason behind this structural change in the price of carbon may be found in the ratio of allocated allowances to actual emissions: as all installations surrendered their quotas and sent their information to the regulator, it could be assessed for the first time that the carbon market was over-supplied, or "over-allocated".

As too many allowances were obviously distributed during the first phase going from 2005 to 2007, economic agents have rationally integrated this reliable information in the price signal of $\mathrm{CO}_{2}$, which has broadly fluctuated ever since in the range of fifteen to twenty euros per ton. 
Alberola et al. (2008a) provide a rigorous econometric analysis of such institutional effects, based on the detection of structural changes in the data, which may be dated back to the announcements by the European Commission during the so-called "first compliance event", which is due to happen on a yearly basis by May 15. Chevallier et al. (2009) extended this analysis to the 2006 compliance event by using option price data.

\subsection{Banking restrictions}

Another equally important effect of institutional decisions, which is often disregarded by analysts and academics, is the decision by the European Commission to ban the transfer of any banked or borrowed allowances from phase I (2005-2007) to phase II (2008-2012). As a consequence, any allowances in surplus as of December 31, 2007 would be worthless on January 1, 2008. The main reason behind that decision may be found in Alberola and Chevallier (2009), who advocate that the European Commission did not want to transfer market design imperfections from the "warmup" period of the scheme to the corresponding period of commitment of the Kyoto Protocol.

Therefore, the banking instrument, which allows industrial operators to smooth emissions and to manage their stock of allowances in a flexible inter-temporal way (see Chevallier (2011a) for a theoretical literature review), has been "sacrificed" in October 2006 in an official press release from the European Commission. From that date until the end of phase I, two price signals have been coexisting: $\mathrm{CO}_{2}$ spot and futures prices valid for phase I which were gearing towards zero (their actual value as of December 2007), and $\mathrm{CO}_{2}$ futures prices valid for phase II fluctuating in the range of twenty euros (with a perception of increased allowance scarcity during 2008-2012).

Paolella and Taschini (2008) have shown how to model the properties of $\mathrm{CO}_{2}$ spot returns during this very specific period of the end of phase I. On this topic, it is also worth highlighting the important theoretical contribution by Daskalakis et al. (2009) under the form of an explicit modeling of the effects of banning banking on pricing $\mathrm{CO}_{2}$ futures prices during the first phase. Next, we detail the inter-relations between $\mathrm{CO}_{2}$ and energy market prices.

\section{ENERGY PRICES \& WEATHER}

This section first reviews the links between "traditional" energy markets (oil, gas, coal, electricity) and the latest energy market to date created by environmental regulation, i.e. the carbon market. Then, we focus on the fuel-switching behavior in the electricity sector, which has a central role in shaping the price of carbon under current market conditions. Third, we detail the role played by (unanticipated) weather events.

\subsection{The influence of oil, gas, and coal prices}

Based on economic analysis (essentially demand and supply fundamentals), Christiansen et al. (2005) have identified the following factors as being the price determinants in the EU ETS: policy and regulatory issues; market fundamentals, including the emissions-to-cap ratio, the role of fuel-switching, weather and production levels. Mansanet-Bataller et al. (2007) and Alberola et 
al. (2008a) were the first analyses to uncover econometrically the relations between energy markets and the $\mathrm{CO}_{2}$ price. Based on phase I spot and futures data, the former group of authors establishes that carbon prices in the EU ETS are linked to fossil fuel (e.g., oil, gas, coal) use. By using an extended dataset, the latter group of authors emphasizes that the nature of this relationship between energy and carbon prices varies depending on the period under consideration, and the major influence of institutional events (as detailed above).

Bunn and Fezzi (2009) further quantify the mutual interactions of electricity, gas and carbon prices in the UK. By using a structural, co-integrated vector error-correction model, they derive the dynamic pass-through of carbon prices into electricity prices, and the response of electricity and carbon prices to shocks in the gas price. Finally, it is worth highlighting the work by Hintermann (2010), who derives a structural model of the allowance price under the assumption of efficient markets and examines the extent to which this variation in price can be explained by marginal abatement costs.

\subsection{Power producers' fuel-switching behavior}

Obviously, the demand for fossil fuels depends on their absolute as well as relative prices. From that perspective, the marginal fuel-switching costs from highly carbon-intensive sources of energy (such as coal) to lower carbon-intensive sources for power and heat generation (such as gas) constitute another important determinant of the $\mathrm{CO}_{2}$ price. As a general rule-of-thumb, carbon abatement in the short-run heavily depends on the behavior of power and heat operators, who are the main actors under the EU ETS (with over fifty percent of emissions capped by the scheme). Moreover, emissions abatement costs from the power sector are assumed to be the lowest compared to other sectors, based on fuel-switching from coal to gas. Among other contributions, we may cite here Delarue and D'haeseleer (2007), Alberola et al. (2008a), and Keppler and Mansanet-Bataller (2010) who have separately studied these causalities between $\mathrm{CO}_{2}$ and electricity variables (such as clean dark and clean spark spreads, and the switch price) during the first phases of the EU ETS.

On this topic, the interested reader may refer as well to Delarue et al. (2010) for a useful topography of abatement by fuel-switching in the European power sector, based on the ESimulate model.

\subsection{The role played by temperatures and extreme weather events}

As outlined by Christiansen et al. (2005), Mansanet-Bataller et al. (2007), Alberola et al. (2008) and Hintermann (2010), $\mathrm{CO}_{2}$ prices are also affected by unexpected climatic variations, including temperatures, rainfalls, and wind. For instance, cold winters (hot summers) increase the need for heating (cooling) by using electricity. When departing from seasonal averages, Alberola et al. (2008a) show that extreme (and essentially unanticipated) temperatures events have a statistically significant effect on carbon price changes. Furthermore, rainfalls, wind speed and hours of sunshine directly affect the share of power generated by carbon-free heat generation from hydropower, wind and solar energy. Taken together, these factors may contribute to explain why the weather is widely acknowledged to play an important role in shaping the price of carbon. 
More research is needed in that direction, namely by gathering more extensive datasets at the European level, and by considering explicitly nonlinearities in the data (as temperatures events may have a significant effect on the price of carbon above or below a given threshold for example). In the next section, we introduce the $\mathrm{CO}_{2}$ price fundamentals linked to the global macroeconomic environment.

\section{MACROECONOMIC AND FINANCIAL MARKET SHOCKS}

In what follows, we detail the links that have been identified in previous literature between the price of $\mathrm{CO}_{2}$ on the one hand, and macroeconomic and financial markets on the other hand. Of particular interest for future researchers will be to assess comprehensively the impact of the economic recession on the carbon market.

\subsection{Industrial production}

Based on the characteristics of the global economic context and changes in industrial production in EU ETS sectors during 2005-2007, Alberola et al. (2008b, 2009) provide the first rigorous econometric exercises aimed at disentangling the potential impacts ranging from production to environmental conditions on carbon prices. This relationship may be understood intuitively: as industrial production increases, associated $\mathrm{CO}_{2}$ emissions increase, and therefore more $\mathrm{CO}_{2}$ allowances are needed by operators to cover their emissions. This economic logic results in carbon price increases ceteris paribus. The authors show empirically that fluctuations in the level of economic activity are a key determinant of the level of carbon price returns in the combustion, paper and iron sectors (which account for nearly eighty percent of allowances allocated), and in four countries (Germany, Spain, Poland, UK).

More recently, Declercq et al. (2011) investigate the impact of the economic recession on $\mathrm{CO}_{2}$ emissions in the European power sector during the years 2008 and 2009. Based on a counterfactual scenario for the demand for electricity, the $\mathrm{CO}_{2}$ price, and fuel prices, their simulations demonstrate that an emissions reduction of about 150 million ton may be expected from the European power sector during the period as a consequence of the recession.

\subsection{Macroeconomic and financial markets indicators}

Interestingly, several studies uncover some econometric links between the carbon market and several indicators related to macroeconomic and financial markets. Oberndorfer (2009) has first tackled this issue from the angle of the stock markets. The author shows that $\mathrm{CO}_{2}$ price changes and stock returns of the most important European electricity corporations are positively related. This effect is particularly strong for the period of carbon market shock in early 2006 (as detailed above), and differs with respect to the countries where the electricity corporations analysed are headquartered. Next, the article by Chevallier (2009) has provided a more comprehensive treatment of the relationship between the carbon market on the one hand, and stock and bond markets on the other hand. By estimating various volatility models for the carbon price with 
standard macroeconomic risk factors, the authors documents that that carbon futures returns may be weakly forecast on the basis of two variables from the stock and bond markets, i.e. equity dividend yields and the "junk bond" premium. Finally, we may cite in this strand of literature the paper by Chevallier (2011b), who assesses the transmission of international shocks to carbon spot and futures carbon prices by using a broad dataset of macroeconomic, financial and commodities indicators. According to the economic theory, the author shows that carbon prices tend to respond negatively to an exogenous recessionary shock in global economic indicators.

Last but not least, note that the article by Mansanet-Bataller et al. (2011) contains an updated study on the main energy markets and macroeconomic fundamentals of $\mathrm{CO}_{2}$ prices during Phase II, along with an analysis of the Kyoto Protocol's Certified Emissions Reductions (CERs), which are valid for compliance under the EU ETS and may yield to arbitrage strategies by market participants.

However, more work is needed on this topic, especially to understand the adjustment process of carbon prices to the macroeconomic environment, for instance by focusing on the underlying nonlinearities of the data. As of today's state-of-the-art literature, economic activity is perhaps the most obvious and least understood driver of $\mathrm{CO}_{2}$ price changes.

\section{CONCLUDING REMARKS}

While the world's international climate policy negotiations have never been so blurred, the European carbon market is functioning since 2005, and has been confirmed to operate by the European Commission at least until 2020. In this context, an updated literature review on the pricing mechanisms for $\mathrm{CO}_{2}$ seems both necessary and useful. By parsing though the recent academic literature, this paper shows that some fundamentals have been identified and confirmed by many empirical studies to date: policy and regulatory issues; market fundamentals (including the emissions-to-cap ratio, the role of fuel-switching, weather); and macroeconomic activity. While more research needs to be pursued concerning the adjustment of the price of carbon to the global economic recession, these studies may be helpful for policy makers, analysts and industrial operators regulated by the EU ETS. As a deeper knowledge of the complex pricing mechanisms at stake is gained, more accurate price forecasts and policy recommendations can indeed be formulated. 


\section{REFERENCES}

Alberola, E., \& Chevallier, J. (2009). European Carbon Prices and Banking Restrictions: Evidence from Phase I (2005-2007). The Energy Journal 30(3), 51-80.

Alberola, E., Chevallier, J., \& Chèze, B. (2008a). Price Drivers and Structural Breaks in European Carbon Prices 2005-07. Energy Policy 36(2), 787-797.

Alberola, E., Chevallier, J., \& Chèze, B. (2008b). The EU Emissions Trading Scheme: the Effects of Industrial Production and $\mathrm{CO}_{2}$ Emissions on European Carbon Prices. International Economics $116,93-126$.

Alberola, E., Chevallier, J., \& Chèze, B. (2009). Emissions Compliances and Carbon Prices under the EU ETS: A Country Specific Analysis of Industrial Sectors. Journal of Policy Modeling 31(3), 446-462.

Bunn, D.W., \& Fezzi, C. (2009). Structural interactions of European carbon trading and energy prices. Journal of Energy Markets 2(4), 53-69.

Chevallier, J. (2009). Carbon futures and macroeconomic risk factors: A view from the EU ETS. Energy Economics 31(4), 614-625.

Chevallier, J. (2011a). Banking and Borrowing in the EU ETS: A Review of Economic Modelling, Current Provisions and Prospects for Future Design. Journal of Economic Surveys, forthcoming. doi: 10.1111/j.1467-6419.2010.00642.x

Chevallier, J. (2011b). Macroeconomics, finance, commodities: Interactions with carbon markets in a data-rich model. Economic Modelling 28(1-2), 557-567

Chevallier, J., Ielpo, F., \& Mercier, L. (2009). Risk Aversion and Institutional Information Disclosure on the European Carbon Market: a Case-Study of the 2006 Compliance Event. Energy Policy 37(1), 15-28.

Christiansen, A.C., Arvanitakis, A., Tangen, K., \& Hasselknippe, H. (2005). Price determinants in the EU emissions trading scheme. Climate Policy 5, 15-30.

Convery, F.J. (2009). Reflections - The Emerging Literature on Emissions Trading in Europe. Review of Environmental Economics and Policy 3(1), 121-137.

Convery, F.J., \& Redmond, L. (2007). Market and Price Developments in the European Union Emissions Trading Scheme. Review of Environmental Economics and Policy 1(1), 88-111.

Daskalakis, G., Psychoyios, D., \& Markellos, R.N. (2009). Modelling $\mathrm{CO}_{2}$ emission allowance prices and derivatives: Evidence from the European trading scheme. Journal of Banking and Finance 33(7), 1230-1241.

Declercq, B., Delarue, E., \& D'haeseleer, W. (2011). Impact of the economic recession on the European power sector's $\mathrm{CO}_{2}$ emissions. Energy Policy 39, 1677-1686.

Delarue, E.D., \& D'haeseleer, W.D. (2007). Price determination of ETS allowances through the switching level of coal and gas in the power sector. International Journal of Energy Research 31, 1001-1015. 
Delarue, E.D., Ellerman, A.D., \& D'haeseleer, W.D. (2010). Robust MACCs? The topography of abatement by fuel switching in the European power sector. Energy 35(3), 1465-1475.

Ellerman, A.D., \& Buchner, B.K. (2007). The European Union Emissions Trading Scheme: Origins, Allocation, and Early Results. Review of Environmental Economics and Policy 1(1), 6687.

Ellerman, A.D., \& Buchner, B.K. (2007). Over-Allocation or Abatement? A Preliminary Analysis of the EU ETS Based on the 2005-06 Emissions Data. Environmental and Resource Economics $41,267-287$.

Ellerman, A.D., Convery, F., \& De Perthuis, C. (2010). Pricing Carbon: The European Union Emissions Trading Scheme. Cambridge University Press, Cambridge, UK.

Hintermann, B. (2010). Allowance price drivers in the first phase of the EU ETS. Journal of Environmental Economics and Management 59, 43-56.

Keppler, J.H., \& Mansanet-Bataller, M. (2010). Causalities between $\mathrm{CO}_{2}$, electricity, and other energy variables during phase I and phase II of the EU ETS. Energy Policy 38(7), $3329-3341$.

Mansanet-Bataller, M., Chevallier, J., Hervé-Mignucci, M., \& Alberola, E. 2011. EUA and sCER Phase II Price Drivers: Unveiling the reasons for the existence of the EUAsCER spread. Energy Policy 39(3), 1056-1069.

Mansanet-Bataller, M., Pardo, A., \& Valor, E. (2007). CO2 Prices, Energy and Weather. The Energy Journal 28, 73-92.

Oberndorfer, U. (2009). EU Emission Allowances and the stock market : Evidence from the electricity industry. Ecological Economics 68, 1116-1126.

Paolella, M.S., \& Taschini, L. (2008). An econometric analysis of emission allowance prices. Journal of Banking and Finance 32(10), 2022-2032.

Zhang, Y.J., \& Wei, Y.M. (2010). An overview of current research on EU ETS: Evidence from its operating mechanism and economic effect. Applied Energy 87(6), 1804-1814. 


\section{Biographical Statement:}

Dr. Julien Chevallier is an Assistant Professor of Economics at the University Paris Dauphine, where he undertakes research and lectures on time-series econometrics applied to financial, commodities and energy markets, including carbon markets (EU ETS, Kyoto Protocol). He is a member of the Center for Geopolitics and Raw Materials (CGEMP) and the Dauphine Economics Lab (LEDa). He is also a Visiting Researcher with EconomiX-CNRS at the University Paris West Nanterre La Défense, and the Grantham Institute for Climate Change at Imperial College London. He received his Ph.D. in Economics from the University Paris West Nanterre La Défense in 2008, and his M.Sc. in Economics from the London School of Economics in 2005. Dr. Chevallier has previously held visiting research positions at the Centre for Economic Performance at the London School of Economics, at Georgetown University, and at the World Bank. He has published articles in leading refereed journals, including Annals of Finance, Economic Modelling, Energy Economics, and The Energy Journal. Furthermore, Dr. Chevallier is currently Associate Editor of the International Journal of Global Energy Issues. 